\title{
Morphological awareness and reading abilities in second- and third-grade Hebrew readers
}

\author{
VERED VAKNIN-NUSBAUM \\ Western Galilee College and University of Haifa
}

Received: November 15, 2016 Accepted for publication: February 16, 2018

\author{
ADDRESS FOR CORRESPONDENCE \\ Vered Vaknin-Nusbaum, Department of Education, Western Galilee College, P.O. Box 2125, Akko, \\ Israel 24121. \\ E-mail: Vered.Vaknin@gmail.com
}

\begin{abstract}
The contribution of morphological awareness to reading comprehension in Hebrew was tested in 100 second- and third-grade students on three types of morphology: inflections, derivations, and construct formation, controlling for vocabulary knowledge. Third graders performed better than second graders on inflectional and construct formation awareness, but only derivations and construct formation predicted success in reading comprehension. Significant differences in reading comprehension but not in orthographic word recognition and phonological decoding were found between students with low and high morphological awareness. The results highlight the importance of examining the unique contribution of different components of morphological awareness to reading comprehension.
\end{abstract}

Keywords: comprehension; construct formation; derivations; Hebrew; inflections; morphological awareness; reading

It is widely accepted that the development of morphological awareness requires increasing familiarity with a wide range of word forms such as inflections and derivations. Inflections are almost fully mastered by second grade (Carlisle, 1995), while derivational systems continue to develop for years (Verhoeven \& Perfetti, 2011). Derivations that are phonetically and semantically transparent (bake-baker) are usually already mastered in first grade, while more complex derivation forms, which are less semantically transparent and involve phonological changes, are usually acquired as late as the beginning of fourth grade (Carlisle, 1995; Tyler \& Nagy, 1989).

Familiarity with morphologically complex words and their derivations is essential for developing and sharpening awareness of structures and grammatical rules regarding their construction. The conscious awareness of the morphemic structure of words and the ability to reflect upon and manipulate that structure is called morphological awareness. Many studies have found morphological awareness to be a good predictor of reading comprehension, in particular awareness of

(C) Cambridge University Press 2018 0142-7164/18 
Vaknin-Nusbaum: Morphological awareness and reading abilities

derivations (Carlisle 1995, p. 194; Kirby et al., 2012). This study examined the contribution of several types of morphological awareness to reading comprehension in second- and third-grade Hebrew speakers while controlling for vocabulary knowledge.

\section{MORPHOLOGICAL AWARENESS AND READING COMPREHENSION IN YOUNG READERS}

The relationship between different morphological tasks and reading comprehension was established in several studies in elementary school-age children (Bowers, Kirby, \& Deacon, 2010; Carlisle, 1995; Goodwin \& Ahn, 2010; Kieffer, 2014; Kuo \& Anderson, 2006; Vaknin, Sarid, \& Shimron, 2016), including children as young as second grade (Apel \& Diehm, 2014; Wolter \& Dilworth, 2014). These findings led researchers to suggest that morphological awareness in young school-age children should be assessed by a range of morphological tasks, including inflections and derivations (Angelelli, Marinelli, \& Burani, 2014; Carlisle, 1995; Nagy, Carlisle, \& Goodwin, 2014; Wolter \& Gibson, 2015).

Most studies of this kind have been conducted in English (Carlisle \& Fleming, 2003; Deacon \& Kirby, 2004; Gonter-Gaustad \& Kelly, 2004; Goodwin \& Ahn, 2010, 2013; Hulme \& Snowling, 2015; Nagy, Berninger, \& Abbot, 2006; Nagy et al., 2014; Nunes \& Bryant, 2011; Rispens, McBride-Chang, \& Reitsma, 2008; Verhoeven \& Carlisle, 2006; Verhoeven \& Perfetti, 2003), a language with relatively simple morphology and deep orthography (Share, 2008; Verhoeven \& Perfetti, 2011). Because the relationship between morphological awareness and reading comprehension might change due to the language's morphological complexity and the transparency of its writing system, this relationship should be researched in other languages that differ in their nature from English (Angelelli et al., 2014; Share, 2008; Verhoeven \& Perfetti, 2011). Nevertheless, studies on different morphological systems and orthographies, such as those in Semitic languages (e.g., Hebrew), are relatively scarce.

The relationship between morphological awareness and reading comprehension could be more evident and may develop at a different pace, perhaps earlier, in languages with a richer and more complex morphology such as Hebrew (Berman, 2002; Ravid \& Malenky, 2001). It is suggested that awareness of morphological structures in such morphologically rich languages is a necessary anchor for reading comprehension (Schiff \& Raveh, 2011; Vaknin-Nusbaum, Sarid, Raveh, \& Nevo, 2016). Studying this relationship with awareness of different morphological forms in young Hebrew readers may expand our understanding of the reading comprehension process in languages with complex morphology. This study examined the contribution of morphological awareness to reading comprehension in Hebrew, a morphologically complex and dense language, in young readers.

\section{HEBREW MORPHOLOGY}

Hebrew is characterized by high morphological density in both its inflectional and its derivational word formation. A noun can be inflected for number, gender, and 
possession by suffixation, and a verb can indicate time, person, and number by prefixes and suffixes. Several prefixes and suffixes can be attached to verbs, nouns, adjectives, and adverbs to construct prepositions such as in and to. For example, the prefix $b a$ "in" + the word bor "hole" forms babor "in the hole" (Ravid, 2006; Shimron, 2006; Vaknin-Nusbaum \& Shimron, 2011).

Hebrew allows inflection and conjugation through both linear and nonlinear combination. Linear word formation is created by a linkage of morphemes to create a word: kadur "ball" + the plural suffix -im forms kadurim "balls." Shulxan "table" + possessive suffix - $i$ forms shulxani "my table." Although linear formation usually characterizes inflections, it also appears in construct formation, which is created by compounding two nouns to derive a nominal phrase: buba mi-niyar "a doll made of paper." Hebrew nonlinear formation, which mainly characterizes verb formation, is created by the combination of consonantal roots with pattern morphemes composed of vowels and sometimes also consonants: maxshev "computer" is created by a derivation in which the root X.SH.V. is interwoven into the pattern $\mathrm{MaCCeC}$ (where the Cs stand for the root letters). This is a nonlinear composition because the root morpheme is inserted into a pattern instead of being linearly attached, as is common in Indo-European languages such as English. Hence, understanding complex words in Hebrew requires sensitivity to both linear and nonlinear morphological structures.

Hebrew morphological density is also reflected in the tendency to use long clusters of bound morphemes (e.g., morphemes that can only be attached to another part of a word and cannot stand alone). Compare the single Hebrew word $k$ 'sh'erehu with the English equivalent of four separate words, when I see him. The information represented in Hebrew by just one word is represented in English by an entire phrase. This feature of Hebrew may sometimes slow the reading comprehension process. Research shows that Hebrew speakers read more slowly than English speakers (Shimron, 2006). It is therefore suggested that knowledge of morphological structures in morphologically rich languages like Hebrew is essential for the reader in word decoding and reading comprehension (Vaknin-Nusbaum, Sarid, Raveh, et al., 2016).

While the Hebrew writing system has complex and rich morphological structures, in contrast to European languages, it is more morphologically transparent in its written forms (Berman, 2002; Ravid \& Malenky, 2001) due to the more transparent representation of some morphemes. The root appears as a complete and continuous letter cluster while the vowels are absent (as in the unpointed Hebrew orthography) or appear as diacritics above and below the root letters (as in the pointed Hebrew orthography), as against being interspersed among the root's consonants (Ravid, 2001, 2002; Ravid \& Bar-On, 2001; Ravid \& Malenky, 2001; Ravid \& Schiff, 2006; Shimron, 2006). ${ }^{1}$ Given the morphological richness on the one hand and the orthographic transparency on the other, the Hebrew readers' sensitivity to morphemes is expected to contribute to the reading process in the early grades of elementary school (Ravid \& Epel-Mashraki, 2007). Morphological transparency may facilitate the reader's identifying written morphemes and lead him to practice awareness of different types of morphological forms together with reading. Such practice helps the reader to extract the appropriate meaning of the word (Wolter \& Dilworth, 2014). 
Vaknin-Nusbaum: Morphological awareness and reading abilities

\section{MORPHOLOGICAL AWARENESS IN HEBREW}

Research shows that Hebrew-speaking children's ability to identify and manipulate morphemic units in words (i.e., their morphological awareness) actually begins to develop in preschool (Berman, 2002; Ravid, 2002) and progresses in elementary school (Levin, Ravid, \& Rapaport 2001; Ravid \& Schiff, 2006; Schiff \& Lotem, 2011). In a study by Kaplan and Ravid (2009), awareness of the root appeared in kindergarten, whereas the ability to pinpoint the root in a new word developed only in elementary school. Awareness of derivations composed of root and pattern morphemes was found in second through sixth graders (Ravid \& Schiff, 2006). They were given the common noun kefel "multiplication" and its derivation maxpela "product" and were expected to form masreta "movie camera" when given seret "a movie." The children developed their morphological awareness gradually and exhibited accelerated developmental changes in derivational morphological awareness in the transition from Grades 2 to 3 and from Grades 4 to 5 .

In another developmental study, Vaknin-Nusbaum, Sarid, and Shimron (2016) reported improvement of plural and possessive inflections in second graders. Children improved their awareness of plural inflections more than their awareness of possessive inflections throughout second grade. Awareness of both inflection types at the beginning of the year predicted greater reading comprehension at the end of the year in these children.

The contribution of awareness of different types of morphological forms was also examined in second and fifth graders (Vaknin-Nusbaum, Sarid, Raveh, et al., 2016). Inflections, derivations, and construct formations were found to correlate with word recognition and reading comprehension at both grade levels. Furthermore, high morphological awareness (HMA) readers exhibited high performance in both inflections and derivations; their reading abilities (word recognition and reading comprehension) were significantly higher than those of readers with low morphological awareness (LMA), who performed particularly poorly on complex forms such as derivations (Vaknin-Nusbaum, Sarid, Raveh, et al., 2016). A relationship between poor reading abilities and LMA was also found in children of low socioeconomic status families (Schiff \& Lotem, 2011) in higher elementary school grades (Ben-Dror, Bentin, \& Frost, 1995; Cohen, Schiff, \& Gillis-Carlebach 1996), and in reading-impaired adolescents (Schiff \& Ravid, 2004) and adults (Schiff \& Ravid, 2007). Despite the relationship found between LMA and poor reading skills in Hebrew, relatively few studies have examined these readers' reading profile.

\section{THE PRESENT STUDY}

Most research on Hebrew has probed the contribution of morphological awareness to single-word recognition (Ben-Dror et al., 1995; Cohen et al., 1996; Schiff $\&$ Ravid, 2004, 2007), with less attention being paid to the connection between morphological awareness and reading comprehension (Vaknin-Nusbaum, Sarid, Raveh, et al., 2016; Vaknin-Nusbaum, Sarid, \& Shimron, 2016). Nor was knowledge of vocabulary controlled for in those studies, despite its known importance 
for morphological awareness and reading comprehension. Rapid growth of vocabulary knowledge has been found to be related to morphological awareness and support-word recognition (Bowers et al., 2010; Kieffer \& Lesaux, 2012; Ramirez, Walton, \& Roberts, 2014). Awareness of different types of morphological forms has been shown to make a unique contribution to reading comprehension (VakninNusbaum, Sarid, Raveh, et al., 2016; Vaknin-Nusbaum, Sarid, \& Shimron, 2016). However, with reference to young readers, research that takes into account differences in age and vocabulary knowledge is lacking (Bowers et al., 2010; Carlisle, 2010; Ouellette \& Beers, 2010). The finding that the developmental pattern of morphological awareness is different for different types of morphological forms (Schiff, Ravid, \& Levy-Shimon, 2011), underscores the need to examine the contribution of each type to reading comprehension at different age levels. This would enable us to characterize the development of awareness of several types of complex morphological forms and the relationship of each to reading comprehension. It may also qualify potential differences in the relationship between derivational morphology and inflectional morphology to reading (Nagy et al., 2014), as well as indicate whether complex forms, including derivations, correlate positively with reading comprehension not only in the higher grades (cf. Verhoeven \& Perfetti, 2011) but also in the elementary grades. In light of these considerations, this study examined the contribution of three types of morphological awareness (inflections, derivations, and construct formation) to reading comprehension in second- and third-grade Hebrew speakers while controlling for vocabulary knowledge.

\section{RESEARCH QUESTIONS AND HYPOTHESES}

The study was designed to answer the following research questions:

1. Does the contribution of the three types of morphological awareness (inflections, derivations and construct formation) to reading comprehension change with development (between second and third grade) after controlling for vocabulary knowledge?

2. Does morphological awareness (i.e., the contrast between LMA and HMA) relate to students' reading profiles? Do second and third graders have similar profiles?

The following research hypotheses form the basis of the study:

1. Each of the three types of morphological awareness will make a unique contribution to reading comprehension after controlling for vocabulary, and this contribution will be evident as early as second grade.

2. HMA readers will perform better than LMA readers on all examined reading measures.

3. Third graders will perform better than second graders in morphological awareness due to their greater experience with reading and development of morphological awareness. 
Vaknin-Nusbaum: Morphological awareness and reading abilities

\section{METHOD}

\section{Participants}

Participants were 100 students from two elementary schools: 60 second graders, 23 girls and 37 boys, 7 to 8 years old, from two classes; and 40 third graders, 21 boys and 19 girls, 8 to 9 years old, from two classes; all were native Hebrew speakers. This age was chosen based on evidence that Hebrew readers begin to use morphemic cues in their reading during second grade (Bar-On, 2010; VakninNusbaum, Sarid, Raveh, et al., 2016; Vaknin-Nusbaum, Sarid, \& Shimron, 2016) and that the complexity of Hebrew morphology compels children to rely on different types of morphological knowledge to comprehend a text as early as second grade (Vaknin-Nusbaum, Sarid, \& Shimron, 2016).

The schools were located in midlevel socioeconomic neighborhoods in the north of Israel. Homeroom teachers reported no specific language, attention, or developmental deficits among the participants. Gender distribution did not differ by class, $\chi^{2}(1)=0.83, p=.363$. Parents provided written informed consent for their child's participation.

\section{Research tools}

Morphological awareness test. Morphological awareness was examined by a four-part test: plural inflections, possessive inflections, derivations, and construct formation, designed for elementary school children (Vaknin-Nusbaum, Sarid, Raveh, et al., 2016; Vaknin-Nusbaum, Sarid, \& Shimron, 2016) and based on Nunes, Bryant, and Bindman's (1997) word-pairs task. For each of the four morphological forms, children were presented with a pair of words and were asked to choose a new word from two given options to complete the second pair. The stimuli consisted of common and familiar words in everyday use in the spoken language (e.g., table, window, and ball), confirmed by the teacher. The test was also reviewed by two reading morphology experts who validated each of its parts. The test was presented in pointed Hebrew, which gives information about vowels. After receiving a printed example, students were instructed, with no time limit, to circle the correct answer in each part as follows:

Plural inflections (8 items: four regular, four irregular). The students were instructed to identify the correct regular plural inflection (e.g., kadur exad "one ball," harbe "many" kadurim / *kadurot) and the correct irregular plural inflection (e.g., beytza "one egg," harbe "many" beytzim / *beytzot) from two options separated by a slash. The options were a plural form with a feminine suffix or a masculine suffix.

Possessive inflections ( 8 items). Students were instructed to identify the correct possessive inflection (e.g., Hatik shelahem hu ... tikam / tiko "Their backpack is ... their backpack / his backpack") from two options separated by a slash. Note that unlike in English, in Hebrew the possessive form is expressed as a bound suffix specific to each possessive inflection. Cronbach $\alpha$ reliability for both inflection parts was 0.81 for second graders and 0.83 and 0.88 , respectively, for third graders. The correlation between the two parts (plural and possessive) was 
Vaknin-Nusbaum: Morphological awareness and reading abilities

significant $(r=.34, p=.002)$, and as there was no significant difference between them, $t(99)=1.43, p=.156$, they were combined.

Derivations (6 items). All items were regular and fully triconsonantal with no missing elements (Ravid, 1995; Schwarzwald, 2001). Following an example, the students were required to choose the correct infinitive transformation out of the two given options separated by a slash. The distractor was a word with the same root as the root source, but not with the same pattern (e.g., lishmor-shmira "to guardguarding" is like likshor-kshira / kesher "to tie-tying / a tie"). The correct choice appears here in bold type. Note that in Hebrew these word pairs are examples of derivations. To identify the correct derivation (e.g., kshira), the child had to analyze the morphological root-and-pattern structure of the example, locate the new root (e.g., the root K.SH.R of the word likshor), and weave it into the morphemic pattern introduced in the example (e.g., the pattern of the word shmira: $\mathrm{CCiCa}$ ). Cronbach $\alpha$ reliability for the derivation test for second graders was 0.80 and for third graders it was 0.65 . The $\alpha$ level for third grade was somewhat low but acceptable.

Construct formation ( 6 items). Students were asked to identify the correct formation of the construct (e.g., buba mi-niyar ["a doll made of paper"]: bubat niyar/ bet bubot ["a paper doll / a doll's house"]. The morphological test was presented to all readers in a pointed (i.e., with diacritics) form. Cronbach $\alpha$ reliability for construct formation for second graders was 0.95 and for third graders it was 0.76 .

Correlations between the three morphological subtests were found to be in the range of 0.38 and 0.49 , which suggests that the three morphological types are related to each other but also different. The morphological awareness score of each subtest was the percent of correct answers out of the items in that subtest.

Reading and vocabulary tests (age normed). The Hebrew assessment battery of reading measures, Elul (Elul test; Shatil, Nevo, \& Breznitz, 2007), consists of tests for orthographic word recognition, phonological decoding, reading comprehension, and vocabulary. This battery was developmentally designed, with ageappropriate normed versions from first through ninth grades. It was developed and validated on 495 second graders and 103 third graders (Shatil et al., 2007) and has been used in numerous studies examining reading and language skills in elementary schools (e.g., Bar-Kochva 2013; Horowitz-Kraus, Cicchino, Amiel, Holland, \& Breznitz, 2014; Nevo, Brande, \& Shaul, 2015; Vaknin-Nusbaum et al., 2016).

ORTHOGRAPHIC WORD RECOGNITION. Orthographic word recognition (apart from pseudoword decoding) is an important measure of reading comprehension (Ouellette \& Beers, 2010). In this test, students were asked to circle words that named animals (familiar to them from their spoken language) within a limited time frame. The test for second graders had 80 words, 25 (maximal score) of which represented animals, and the time limit was 2 min and $32 \mathrm{~s}$. The test for third graders had 100 words, of which 31 (maximum score) represented animals, and the time limit was $1 \mathrm{~min}$ and $20 \mathrm{~s}$. Orthographic word recognition scores were calculated as the percentage of the total number of correct words for each grade level. None of the target words were inflections. The test yielded Cronbach $\alpha$ of 0.94 for both second and third graders. 
Vaknin-Nusbaum: Morphological awareness and reading abilities

PHONOLOGICAL DECODING. Phonological decoding is one of the most critical skills for successful reading acquisition, and often differentiates good and poor readers. It is usually measured by examining children's nonword reading performance (Share, 1995; Ziegler \& Goswami, 2005). In this test, the stimuli were homophonic pseudowords. Students were instructed to circle pseudowords that sounded like food (bread/bred). The test enabled children to associate novel letter sequences and familiar words by accessing their phonological lexicon. The test for second graders contained 78 pseudowords, 22 of which sounded like food items, and the time limit was $3 \mathrm{~min}$ and $5 \mathrm{~s}$. The test for third graders contained 78 pseudowords, 22 of which sounded like food items, and the time limit was 2 min and $49 \mathrm{~s}$. Note that although the test is identical for both grade levels, there is a difference in the time limit as third graders are expected to be more fluent decoders. Phonological decoding scores were calculated as the percentage of the total number of correct words for each grade level. The test yielded Cronbach $\alpha$ of 0.89 for second graders and 0.86 for third graders. Note that both orthographic word recognition and phonological decoding tests contain morpheme patterns, which may suggest that knowing them enables the recognition and reading of the words.

READING COMPREHENSION. Students were asked to read two texts in the allotted time and answer true/false questions about their content. Second graders read two texts: the first ("Udi and Roy") contained 44 words and test time was $3 \mathrm{~min}$ and $2 \mathrm{~s}$; the second ("Sweet and Sour Popsicle") had 67 words and test time was $3 \mathrm{~min}$ and $32 \mathrm{~s}$. Students were asked to answer 8 right/wrong questions on each text. Third graders read two texts: the first ("Uri") had 84 words and the test time was 2 min and $54 \mathrm{~s}$; the second ("The Day Nightingale and the Night Nightingale") had 97 words and the test time was 3 min and $12 \mathrm{~s}$. Students were asked to answer 10 right/wrong questions on each text. Considering that most Hebrew words consist of at least two morphemes (a root and a pattern) and that Hebrew is characterized by a dense morphology, the comprehension texts in this study also contained morphologically complex words. The percentage of correct answers was calculated for each student. The test yielded Cronbach $\alpha$ of 0.88 for second graders and 0.89 for third graders.

VOCABULARY. Students were asked to look at four pictures and choose the one that represented the given word. The test had 26 words arranged by level of familiarity. The test yielded Cronbach of 0.82 for second and third graders.

All Elul tests for second and third grades were pointed, and variables were converted to a $0-100$ scale.

\section{Procedure}

Reading and morphological awareness tests were administered by the researchers in the students' homerooms to groups of 15 students in the middle of the academic year (February). The order of the tests was word recognition, phonological decoding, reading comprehension, vocabulary, and morphological awareness. Each pupil was given a notebook and asked to listen carefully to the instructions, which 
were read out by the researcher; they also appeared at the top of each test sheet. Written examples were presented first, and the test began when the training items had been answered correctly. When the time limit of each test was reached, participants were asked to stop working. The number of correct answers was calculated for each test separately. Administering the tests took a total of about $40 \mathrm{~min}$.

\section{Data analysis}

Means and standard deviations of the study variables and correlations among them were calculated, after which grade differences in the study variables were examined with a series of $t$ tests. Multiple regression analyses were conducted to assess the contribution of morphological awareness to the three reading measures: word recognition, phonological decoding, and reading comprehension. Grade and vocabulary were entered first and the three types of morphological awareness second. Next, cluster analysis was used to divide the students into two subgroups according to their morphological awareness, high or low. $K$-means clustering was used, a priori defining two clusters. In line with this definition, two centroids were defined, and each case was associated with the nearest centroid. All cases having been assigned, the centroids were recalculated (a posteriori) and cases were replaced according to the nearest centroid criterion. This procedure was repeated until the centroids were not changed. Differences in reading abilities (word recognition, phonological decoding, and reading comprehension) by level of morphological awareness were analyzed by multivariate analysis of variance, controlling for grade level and vocabulary. Finally, partial correlations between the types of morphological awareness and the outcome variables were used, controlling for grade level and vocabulary, within the levels of morphological awareness.

\section{RESULTS}

\section{Descriptive preliminary results}

Reading comprehension and orthographic word recognition were generally good (means $74 \%$ and $88 \%$, respectively), while phonological decoding was lower $(60 \%$; Table 1). The morphological awareness components of terms of inflections and construct formation were good ( $91 \%$ and $75 \%$, respectively), while the average score for derivations was lower $(48 \%)$. Mean vocabulary score was good as well (75\%). Positive and significant correlations were found between reading comprehension and morphological awareness, and between orthographic word recognition and morphological awareness (except inflections). Weak correlations were found between phonological decoding and derivations. Both reading comprehension and orthographic word recognition were positively related to vocabulary; therefore, vocabulary was controlled for in subsequent analyses.

\section{Grade-level differences}

$T$ tests were used to examine differences in the study variables by grade (Table 2). Significant differences were found for reading comprehension, phonological 
Table 1. Means (\%), standard deviations, and correlations for the study variables $(N=100)$ : word recognition, phonological decoding, reading comprehension, and three types of morphological awareness

\begin{tabular}{|c|c|c|c|c|c|c|c|c|}
\hline & $\begin{array}{l}\text { Means } \\
(S D)\end{array}$ & $\begin{array}{l}\text { Word } \\
\text { recognition }\end{array}$ & $\begin{array}{l}\text { Phonological } \\
\text { decoding }\end{array}$ & $\begin{array}{l}\text { Morphological awareness } \\
\text { (total score) }\end{array}$ & Inflections & Derivations & $\begin{array}{l}\text { Construct } \\
\text { formation }\end{array}$ & Vocabulary \\
\hline Reading comprehension & $\begin{array}{c}73.64 \\
(20.34)\end{array}$ & $.28 * *$ & .19 & $.53 * * *$ & $.35 * * *$ & $.40 * * *$ & $.47 * * *$ & $.21^{*}$ \\
\hline Word recognition & $\begin{array}{c}87.69 \\
(19.13)\end{array}$ & & $.47 * * *$ & $.41 * * *$ & .19 & $.36 * * *$ & $.34 * * *$ & $.35 * * *$ \\
\hline Phonological decoding & $\begin{array}{l}59.77 \\
(26.98)\end{array}$ & & & .19 & .12 & $.25^{*}$ & .06 & .16 \\
\hline $\begin{array}{l}\text { Morphological awareness } \\
\text { (total) }\end{array}$ & $\begin{array}{c}71.31 \\
(22.21)\end{array}$ & & & & $.67 * * *$ & $.82 * * *$ & $.81 * * *$ & $.35 * * *$ \\
\hline Inflections & $\begin{array}{c}90.61 \\
(14.38)\end{array}$ & & & & & $.38 * * *$ & $.49 * * *$ & $.30 * *$ \\
\hline Derivations & $\begin{array}{c}48.00 \\
(36.64)\end{array}$ & & & & & & $.39 * * *$ & $.23^{*}$ \\
\hline Construct formation & $\begin{array}{c}75.33 \\
(32.87)\end{array}$ & & & & & & & $.32 * *$ \\
\hline Vocabulary & $\begin{array}{c}74.73 \\
(15.02)\end{array}$ & & & & & & & \\
\hline
\end{tabular}

$* p<.05 . * * p<.01 . * * * p<.001$ 
Vaknin-Nusbaum: Morphological awareness and reading abilities

Table 2. Means (\%) and standard deviations for the study variables by grade $(N=100)$

\begin{tabular}{lcccc}
\hline \hline & $\begin{array}{c}\text { Second } \\
\text { grade } \\
M(S D)\end{array}$ & $\begin{array}{c}\text { Third } \\
\text { grade }\end{array}$ & & \\
& $M(S D)$ & $t$ & $d$ \\
\hline Reading comprehension & 70.31 & 78.63 & $t(98)=2.03^{*}$ & 0.43 \\
& $(22.66)$ & $(15.19)$ & & \\
Word recognition & 89.27 & 85.32 & $t(98)=-1.01$ & 0.20 \\
& $(17.28)$ & $(21.63)$ & & \\
Phonological decoding & 70.30 & 53.98 & $t(98)=-5.42^{* * *}$ & 0.68 \\
& $(23.05)$ & $(24.86)$ & & 0.46 \\
Morphological awareness & 67.47 & 77.08 & $t(95.48)^{\mathrm{a}}=2.40^{*}$ & 0.50 \\
(total score) & $(25.60)$ & $(14.29)$ & & \\
Inflections & 87.96 & 94.58 & $t(91.44)^{\mathrm{a}}=2.61^{*}$ & 0.01 \\
& $(16.84)$ & $(8.30)$ & & \\
Derivations & 47.78 & 48.33 & $t(98)=0.07$ & 0.73 \\
& $(38.63)$ & $(33.93)$ & & \\
Construct formation & 66.67 & 88.33 & $t(93.40)^{\mathrm{a}}=3.82^{* * *}$ & \\
& $(37.08)$ & $(19.32)$ & & \\
Vocabulary & 72.82 & 77.60 & $t(79.86)^{\mathrm{a}}=1.83$ & 0.34 \\
& $(18.44)$ & $(6.68)$ & & \\
\hline \hline
\end{tabular}

${ }^{a}$ Here, $t$ for unequal variances. ${ }^{*} p<.05 . * * p<.01 . * * * p<.001$.

decoding, and morphological awareness (total score), inflections, and construct formation. Third graders scored higher than second graders on reading comprehension and morphological awareness (and its types), whereas second graders scored higher on phonological decoding. Grades did not differ on orthographic word recognition, derivations, or vocabulary.

\section{Predicting reading comprehension}

A multiple hierarchical regression analysis (OLS) was performed to assess the contribution of morphological awareness to reading comprehension, over and above orthographic word recognition, phonological decoding, and vocabulary. Grade was entered first as a dummy variable $(0=$ second grade, $1=$ third grade $)$, as were the scores for vocabulary, orthographic word recognition, and phonological decoding. The three types of morphological awareness were entered second, separately (Table 3).

To examine the unique contribution of morphological awareness to reading comprehension beyond the contribution of grade level, vocabulary, word recognition, and phonological decoding, multiple regression was conducted controlling for those factors. The regression model was found significant, Adj. $R^{2}=.27, F$ $(7,92)=6.22, p<.001$. Thirteen percent of the variance in reading comprehension was explained by the morphological predictors assessed $(p<.001)$. Derivations and construct formation were positively related to reading comprehension $(\beta=0.22, p=.035$ and $\beta=0.28, p=.014$, respectively) beyond grade level, 
Vaknin-Nusbaum: Morphological awareness and reading abilities

Table 3. Multiple regression predicting reading comprehension $(N=100)$

\begin{tabular}{lrll}
\hline \hline & $B$ & $S E$ & $\beta$ \\
\hline Step 1 & & & \\
Grade & 13.81 & 4.57 & $0.33^{* *}$ \\
Vocabulary & 0.07 & 0.14 & 0.05 \\
Word recognition & 0.19 & 0.12 & 0.17 \\
Phonological decoding & 0.19 & 0.09 & $0.26^{*}$ \\
Adj. $R^{2}$ & & $.14^{* * *}$ & \\
Step 2 & & & \\
Grade & 7.94 & 4.53 & 0.19 \\
Vocabulary & -0.03 & 0.13 & -0.02 \\
Word recognition & 0.03 & 0.12 & 0.03 \\
Phonological decoding & 0.14 & 0.09 & 0.19 \\
Inflections & 0.09 & 0.15 & 0.06 \\
Derivations & 0.12 & 0.06 & $0.22^{*}$ \\
Construct formation & 0.17 & 0.07 & $0.28^{*}$ \\
$\Delta$ Adj. $R^{2}$ & & $.13^{* * *}$ & \\
Model Adj. $R^{2}$ & & $.27 * * *$ & \\
$F(7,92)$ & & $6.22^{* * *}$ & \\
\hline \hline
\end{tabular}

$* p<.05 . * * p<.01 . * * * p<.001$.

vocabulary, orthographic word recognition, and phonological decoding. Higher scores for derivations and construct formation were predictive of better reading comprehension. Inflections were not a significant predictor. The unique contribution of morphological awareness to reading comprehension, after controlling for other related factors, underscores its importance.

In order to examine grade-level differences in the relationship between morphological awareness and reading comprehension, the contribution of the interactions between the types of morphological awareness (standardized) and grade to predicting reading comprehension was examined. All interactions were nonsignificant, revealing no grade-level differences in the relationship between morphological awareness and reading comprehension.

The possible unique contribution of possessive and plural inflections to reading comprehension was also examined. The performance on possessive inflections was higher in third grade $(M=93.89, S D=11.24)$ than in second grade $(M=$ $85.93, S D=24.88), t(88.16)=2.17, p=.033$, but the age-level difference for performance on the plural form was not significant (second grade: $M=90.00$, $S D=15.54$; third grade: $M=95.28, S D=11.22), t(98)=1.85, p=.067$. The correlation between possessive and plural was positive and significant for the total sample $(r=.33, p<.001)$; positive and significant for second grade $(r=.35, p=$ $.005)$; and nonsignificant for third grade $(r=.09, p=.574)$. Using both scores in an additional regression analysis did not yield any significant results (possessive: $\beta=-0.01, p=.993$; plural: $\beta=0.11, p=.316$ ), and derivations and construct formation were still significant predictors of reading comprehension. 
Vaknin-Nusbaum: Morphological awareness and reading abilities

Table 4. Means (\%) and standard deviations for reading comprehension, orthographic word recognition, and phonological decoding by morphological awareness $(N=100)$

\begin{tabular}{lccc}
\hline \hline & HMA & LMA & \\
& $(n=78)$ & $(n=22)$ & $F(1,96)$ \\
& $M(S D)$ & $M(S D)$ & $\left(\eta^{2}\right)$ \\
\hline Reading comprehension & 78.24 & 57.33 & $15.59^{* * * *}$ \\
& $(15.72)$ & $(26.20)$ & $(.140)$ \\
Orthographic word recognition & 89.45 & 81.45 & 2.43 \\
& $(17.70)$ & $(22.89)$ & $(.025)$ \\
Phonological decoding & 60.26 & 58.06 & 2.62 \\
& $(27.60)$ & $(25.21)$ & $(.027)$ \\
\hline \hline
\end{tabular}

Note: HMA, high morphological awareness. LMA, low morphological awareness. $* p<.05$. $* * p<.01 . * * * p<.001$.

\section{Low versus high morphological awareness}

Next, to examine the reading profile of readers with LMA and HMA, the data were divided into the respective subgroups by cluster analysis. This was based on standardized scores of inflections, derivations, and construct formation, resulting in one subgroup with HMA $(M=80.79, S D=13.20, n=78)$ and another with LMA $(M=37.71, S D=13.06, n=22)$. The HMA group had higher means for inflections, derivations, and construct formation $(M=96.23, M=58.76$, and $M=87.39, S D=5.26, S D=33.95$, and $S D=18.65$, respectively) than the LMA group $(M=70.71, M=9.85$, and $M=32.58, S D=18.48, S D=12.24$, and $S D=$ 36.90 , respectively). Most third-grade students had HMA ( $n=37$ of $40,92.5 \%)$ and most second graders had LMA $(n=19$ of $22,86.4 \%), \chi^{2}(1)=8.17, p=.004$.

While the regression analysis looked at the unique contribution of each of the three separate scores of morphological awareness to reading comprehension, the LMA versus HMA groups were based on a combination of all three scores, used to assess the different profile of these two groups of readers, in terms of reading comprehension, orthographic word recognition, and phonological decoding. These differences in reading comprehension, orthographic word recognition, and phonological decoding were analyzed by multivariate analysis of variance, controlling for grade level and vocabulary (Table 4). The multivariate analysis of covariance was significant beyond grade and vocabulary: $F(3,94)=5.29, p=.002$, $\eta^{2}=.145$. A significant difference was found for reading comprehension, attested to by higher scores for students with HMA, while no difference was found for orthographic word recognition or phonological decoding.

\section{DISCUSSION}

The primary goal of the present study was to examine the relationship between different types of morphological awareness and reading comprehension, while controlling for vocabulary in second- and third-grade Hebrew readers. The basic 
Vaknin-Nusbaum: Morphological awareness and reading abilities

assumption underlying this study was that awareness of different types of morphological forms makes a unique contribution to reading comprehension after controlling for vocabulary. Overall, the results reveal that inflections, derivations, and construct formation correlated with reading comprehension, but only derivations and construct formation predicted success in reading comprehension when controlling for vocabulary knowledge. Third graders showed better overall morphological awareness than second graders, and both age groups performed better on inflection tasks than on derivations and construct formation. Significant differences in reading comprehension were found between HMA and LMA readers.

\section{The contribution of morphological awareness to reading comprehension}

Similar to studies conducted in other languages (Apel \& Diehm, 2014; Goodwin \& Ahn, 2010; Rispens et al., 2008; Verhoeven \& Carlisle, 2006; Verhoeven \& Perfetti 2003; Wolter \& Dilworth, 2013), morphological awareness in Hebrew was found here to be related to reading comprehension. Construct formation and derivational awareness were found to be the only predictors of reading comprehension, and together contributed $13 \%$.

The relationship between different types of morphological awareness and reading comprehension reported in previous Hebrew research was found in studies that did not control for vocabulary and phonological decoding (Vaknin, Sarid, Raveh, et al., 2016), two factors also found to be strongly correlated with reading comprehension in other languages (Bowers et al., 2010; García \& Cain, 2013). In this study, phonological decoding was a significant predictor before morphological awareness was entered into the regression analysis but not after. Therefore, the current finding of the unique contribution of morphological awareness to reading comprehension after controlling for other related factors in the regression model underscores the important role morphological awareness plays in comprehending a text. Perhaps once the basic decoding skills are acquired, the reader can use larger linguistic components as morphemes in the process of reading (Nunes \& Bryant, 2011) and may even prefer it.

Despite the unique contribution of construct formation and derivational awareness to predicting reading comprehension, morphological awareness of inflections was not a significant predictor of reading comprehension. It is possible that inflections were not found to be a significant predictor because of a ceiling effect and smaller variability relative to the other morphological measures. Another possible explanation might be the design of this study: unlike previous research conducted in Hebrew, vocabulary, a variable that has a reciprocal relationship to both reading and morphological awareness, was controlled. Previous research indicates that students who show rapid growth of vocabulary knowledge demonstrate rapid growth in morphological awareness (Bowers et al., 2010; Kieffer \& Lesaux, 2012; Ramirez et al., 2014). Since inflections develop relatively earlier than other morphological forms (Ravid, 1995), they might be more related to vocabulary knowledge.

The finding that morphological awareness did not contribute differently to reading comprehension in second and third graders indicates its presence already at early stages of reading. Its contribution becomes greater only in the upper elementary grades as other reading skills develop. Research has shown that more 
attention to morphemes appears after children have acquired proper proficiency in phonological decoding and word recognition (Nunes \& Bryant, 2011). Thus, morphological awareness and the ability to use it in reading comprehension develop in different phases. The fact that young children develop morphological awareness does not necessarily mean that they are able to rely on this ability during reading. Reading itself sharpens the ability to use morphemes consistently during reading (Leong, 1989; Nunes \& Bryant, 2011). It can be assumed that as children become more proficient readers in the upper grades, they are able to rely more on morphemes while reading.

Another possible explanation for the similar contribution of morphological awareness to reading comprehension at both grade levels may be related to the morphological transparency of the Hebrew writing system that facilitates morphological decoding even for very young readers. In this system, vowel signs, if indicated, are usually represented by diacritics above and/or below the written word, leaving the consonantal letter sequence of the root morpheme intact with its letters in the same order. Occasionally a letter that represents a vowel is inserted into the root, but in most cases the order of the root letters remains unchanged (Ravid \& Schiff, 2006; Shimron, 2006). A result of this transparency is that if the reader has developed familiarity with Hebrew roots, word patterns, and affixes, she is probably able to take advantage of this familiarity when reading, thereby improving her reading comprehension (Carlisle, 2007; Nagy et al., 2014; Rispens et al., 2008). This effect of morphological transparency could assist in recognition of words and in reading unfamiliar words or pseudowords constructed from a familiar pattern and/or root and may therefore benefit reading as early as the second and third grades. As reading fluency improves, this transparency makes it possible to use more morphological units as a bridge between the written words and their meanings in the mental lexicon (Frost, 2009, 2011).

\section{Age differences}

Third graders performed better than second graders on the inflection and construct formation awareness tests, but both grades had a similar morphological profile: the best performance was on the inflection task and the worst on the derivation task. This finding agrees with research reported in other languages, showing that morphological awareness develops with age (Carlisle, 2003; Carlisle \& Fleming, 2003; Gonter-Gaustad \& Kelly, 2004; Kirk \& Gillon, 2009; Kuo \& Anderson, 2006; Nagy et al., 2014; Nunes \& Bryant 2011; Rispens et al., 2008), and that second graders are typically in the final stages of mastering the inflection system (Carlisle, 1995). In contrast, second and third graders in this study performed similarly on the derivations task, indicating that this skill develops slower than inflections and construct formation. These findings are consistent with developmental research in Hebrew (Berman, 1997; Ravid, 2006) and in English (Carlisle, 1995; Verhoeven \& Perfetti, 2011), showing that awareness of complex forms such as derivations matures in the later stages of elementary school. The developmental advantage of inflectional awareness may be explained by the more simple construction process: inflections usually entail a minor change in meaning of the base form that preserves its syntactic usage. The appearance of sematic and syntactic changes is 
much more extreme in derivations, which are generally harder to acquire (Carlisle, 1995). Another reason for the developmental differences between inflections and derivations may be Hebrew's unique morphology: the morphological structure of inflections is linear as in European languages while the composition of derivational structures is nonlinear (Berman, 2002; Ravid, 2006).

Derivations distinguishing low from high achievers in reading comprehension were also reported in a previous study (Vaknin-Nusbaum, Sarid, Raveh, et al., 2016), but phonological decoding and vocabulary were not included in the research design. After clustering readers in this study according to HMA and LMA and examining their reading abilities separately, those with LMA were also poor comprehenders despite their average word recognition ability. Their reading comprehension was significantly lower than that of readers with HMA beyond grade and vocabulary, suggesting that they relied more on grapheme-to-phoneme mapping and less on morphological awareness. This possibility is consistent with findings in other languages (Fowler \& Liberman, 1995; Kieffer, 2014; Nagy et al., 2014; Tong, Deacon, \& Cain, 2013) and in Hebrew (Ben-Dror et al., 1995; Cohen et al., 1996; Schiff \& Ravid 2004, 2007; Share, 2005). It shows that poor readers are less sensitive to morphemes, especially with regard to complex forms such as derivations (Tong, Deacon, Kirby, Cain, \& Parrila, 2011). They are less likely to learn about morphemes on their own and to rely on them for reading; they need explicit instruction (Nunes \& Bryant, 2011).

\section{Limitations}

Several limitations should be considered in interpreting the current study's results. The morphological tasks tested awareness of several types of morphological forms, but the number of items in each test was relatively small. In addition, a closer trace of the development of the morphological awareness-reading comprehension relationship necessitates developmental and intervention research in young Hebrew readers, in particular focusing on several types of morphology. Further, larger samples are needed, so that readers with low versus high morphological awareness may be compared within each grade level. Consideration of these factors will improve the design of future morphological instructional programs aimed at developing awareness of age-appropriate sublexical units as a tool for reading recovery. Morphological instructional programs can also be integrated into the formal reading instruction program. As suggested by Bowers et al. (2010), to understand deeply the contribution of morphological awareness to reading comprehension, more cross-linguistic comparative research is needed in orthographies other than English.

In addition, as in this study the morphological awareness tests were conducted in written form, more caution is needed with regard to interpretation of the results. However, the results of morphological awareness tests are consistent with previous results acquired with the same morphological tests also delivered in written form. Because children earn relatively high scores, at least for inflection and construct formation, it is possible to assume that the reading (pairs of frequent words) was not too hard for the students. Each part was presented by the research assistants and the students had to choose the right linguistic form by circling the correct 
answer. There was no time limit: each student could work at his or her own pace. Therefore, it can be assumed that the current results here are illustrative. They are worthy of mention but must be rechecked in replications.

\section{Summary}

The present results illustrate the importance of morphological awareness for reading comprehension in second and third graders. This finding is consistent with results found for other languages, such as English, mainly in upper elementary grade levels (for review, see Goodwin \& Ahn, 2010; Nagy et al., 2014; Verhoeven \& Perfetti, 2011). In a morphologically rich language such as Hebrew, morphological awareness contributes to reading comprehension at relatively early stages of reading acquisition.

Two factors are found to be involved in the relationship between morphological awareness and reading comprehension. The first is the distinction between the three word forms: inflections, derivations, and construct formation. Each type exhibits a different developmental pattern. The second factor is the different reading comprehension profiles of students with HMA and LMA. LMA readers perform poorly in reading comprehension but not in word recognition. Thus, morphological awareness can serve as a good discriminator between good and poor comprehenders (cf. Kieffer, 2014; Wolter \& Gibson, 2015) as early as second grade. An examination of different components of morphological awareness and different types of readers may help in designing early intervention programs that focus mainly on derivations, particularly for struggling and young readers.

Just as young readers need to be aware of the sounds of their language to understand the alphabetic principle, they need to be aware of morphemes to understand the morphemic principle (Nunes \& Bryant, 2011) for better reading comprehension.

\section{NOTE}

1. Hebrew orthography is considered shallow and transparent at the beginning of elementary school when it is presented pointed, and considered deep and opaque when it is presented unpointed.

\section{REFERENCES}

Angelelli, P., Marinelli, C. V., \& Burani, C. (2014). The effect of morphology on spelling and reading accuracy: A study on Italian children. Frontiers in Psychology, 5, 1373.

Apel, K., \& Diehm, E. (2014). Morphological awareness intervention with kindergarteners and first and second grade students from low SES homes: A small efficacy study. Journal of Learning Disabilities, 47, 65-75.

Bar-Kochva, I. (2013). What are the underlying skills of silent reading acquisition? A developmental study from kindergarten to the 2nd grade. Reading and Writing: An Interdisciplinary Journal, 26, 1417-1436.

Bar-On, A. (2010). The role of linguistic knowledge in learning to read non-voweled Hebrew (Doctoral dissertation, Tel Aviv University, Israel). 
Vaknin-Nusbaum: Morphological awareness and reading abilities

Ben-Dror, I., Bentin, S., \& Frost, R. (1995). Semantic, phonologic and morphologic skills in reading disabled and normal children: Evidence from perception and production of spoken Hebrew. Reading Research Quarterly, 30, 876-893.

Berman, R. A. (1997). Preschool knowledge of language: What five-year-olds know about language structure and language use. In C. Pontecorvo (Ed.), Writing development: An interdisciplinary view (pp. 61-76). Amsterdam: Benjamins.

Berman, R. A. (2002). Children's lexical innovations: Developmental perspectives on Hebrew verb structure. In J. Shimron (Ed.), Language processing and acquisition in languages of Semitic, root-based morphology (pp. 243-291). Amsterdam: Benjamins.

Bowers, P. N., Kirby, J. R., \& Deacon, S. H. (2010). The effects of morphological instruction on literacy skills: A systematic review of the literature. Review of Educational Research, 80, 144179.

Carlisle, J. F. (1995). Morphological awareness and early reading achievement. In L. B. Feldman (Ed.), Morphological aspects of language processing (pp. 189-209). Hillsdale, NJ: Erlbaum.

Carlisle, J. F. (2003). Morphology matters in learning to read: A commentary. Reading Psychology, 24, 291-322.

Carlisle, J. F. (2007). Fostering morphological processing, vocabulary development, and reading comprehension. In R. K. Wagner, A. E. Muse, \& K. R. Tannenbaum (Eds.), Vocabulary acquisition: Implications for reading comprehension (pp. 78-103). New York: Guilford Press.

Carlisle, F. J. (2010). Effects of instruction in morphological awareness on literacy achievement: An integrative review. Reading Research Quarterly, 45, 464-487.

Carlisle, J. F., \& Fleming, J. (2003). Lexical processing of morphologically complex words in the elementary years. Scientific Studies of Reading, 1, 239-253.

Cohen, A., Schiff, R., \& Gillis-Carlebach, M. (1996). Hashva'at ha'osher morfologi, hataxbiri v'hanarativi bein yeladim hamitkashim b'kriah l'vein yeladim yodei- k'ro [A comparison of morphologic, syntactic, and narrative richness between children with reading difficulties and good readers]. Megamot, 57, 273-291.

Deacon, S. H., \& Kirby, J. R. (2004). Morphological awareness: Just “more phonological”? The roles of morphological and phonological awareness in reading development. Applied Psycholinguistics, 25, 223-238.

Fowler, A. E., \& Liberman, I. (1995). The role of phonology and orthography in morphological awareness. In L. B. Feldman (Ed.), Morphological aspects of language processing (pp. 157-188). Hillsdale, NJ: Erlbaum.

Frost, R. (2009). Reading in Hebrew vs. reading in English: Is there a qualitative difference? In K. Pugh \& P. McCradle (Eds.), How children learn to read: Current issues and new directions in the integration of cognition, neurobiology and genetics of reading and dyslexia research and practice (pp. 235-254). New York: Psychology Press.

Frost, R. (2011). Looking across orthographies. In P. McCardle, J. R. Lee, O. J. L. Tzeng, \& B. Miller (Eds.), Dyslexia across languages: Orthography and the brain-gene-behavior link. Baltimore, MD: Brooks Publishing.

García, J. R., \& Cain, K. (2013). Decoding and reading comprehension: A meta-analysis to identify which reader and assessment characteristics influence the strength of the relationship in English. Review of Educational Research, 84, 74-111.

Gonter-Gaustad, M., \& Kelly, R. (2004). The relationship between reading achievement and morphological word analysis in deaf and hearing students matched for reading level. Journal of Deaf Studies and Deaf Education, 9, 269-285.

Goodwin, A. P., \& Ahn, S. (2010). A meta-analysis of morphological interventions: Effects on literacy achievement of children with literacy difficulties. Annals of Dyslexia, 60, 183-208.

Goodwin, A. P., \& Ahn, S. (2013). A meta-analysis of morphological interventions in English: Effects on literacy outcomes for school-age children. Scientific Studies of Reading, 17, 257285 . 
Vaknin-Nusbaum: Morphological awareness and reading abilities

Horowitz-Kraus, T., Cicchino, N., Amiel, M., Holland, S. K., \& Breznitz, Z. (2014). Reading improvement in English- and Hebrew-speaking children with reading difficulties after reading acceleration training. Annals of Dyslexia, 64, 183-201.

Hulme, C., \& Snowling, M. (2015). Learning to read: What we know and what we need to understand better. Child Development Perspectives, 7, 1-5.

Kaplan, D., \& Ravid, D. (2009). Hakesher bein kri' at s' farim l'havanat hanikra v'l'kishurim lashoni' im: Mexkar hitpatxuti psikolingwisti [How reading books relates to reading comprehension and linguistic skills: Developmental psycholinguistic research]. Meda'at, 5, 4-18.

Kieffer, M. J. (2014). Morphological awareness and reading difficulties in adolescent Spanish-speaking language minority learners and their classmates. Journal of Learning Disabilities, 47, 44-53.

Kieffer, M. J., \& Lesaux, N. K. (2012). Development of morphological awareness and vocabulary knowledge in Spanish-speaking language minority learners: A parallel process latent growth curve model. Applied Psycholinguistics, 33, 23-54.

Kirby, J. R., Deacon, S. H., Bowers, P. N., Izenberg, L., Wade-Woolley, L., \& Parrila, R. (2012). Children's morphological awareness and reading ability. Reading and Writing, 25, 389-410.

Kirk, C., \& Gillon, T. G. (2009). Integrated morphological awareness intervention as a tool for improving literacy. American Speech-Language-Hearing Association, 40, 341-351.

Kuo, L., \& Anderson, R. C. (2006). Morphological awareness and learning to read: A cross-language perspective. Educational Psychologist, 41, 161-180.

Leong, C. K. (1989). Productive knowledge of derivational rules in poor readers. Annals of Dyslexia, 39, 94-115.

Levin, I., Ravid, D., \& Rapaport, S. (2001). Morphology and spelling among Hebrew-speaking children: From kindergarten to first grade. Journal of Child Language, 28, 741-772.

Nagy, W. E., Berninger, V. W., \& Abbot, R. C. (2006). Contribution of morphology beyond phonology to literacy outcomes of upper elementary and middle-school students. Journal of Educational Psychology, 98, 134-147.

Nagy, W. E., Carlisle, J. F., \& Goodwin, A. P. (2014). Morphological knowledge and literacy acquisition. Journal of Learning Disabilities, 47, 3-12.

Nevo, E., Brande, S., \& Shaul, S. (2015). The effects of two different reading acceleration training programs on improving reading skills of second graders. Reading Psychology, 37, 533-546.

Nunes, T., \& Bryant, P. (2011). Morphemic approaches for reading words. In R. E. O’Connor \& P. F. Vadasy (Eds.), Handbook of reading interventions (pp. 88-112). New York: Guilford Press.

Nunes, T., Bryant, P., \& Bindman, M. (1997). Morphological spelling strategies: Developmental stages and processes. Developmental Psychology, 33, 637.

Ouellette, G., \& Beers, A. (2010). A not-so-simple view of reading: How oral vocabulary and visualword recognition complicate the story. Reading and Writing, 23, 189-208.

Ramirez, G., Walton, P., \& Roberts, W. (2014). Morphological awareness and vocabulary development among kindergarteners with different ability levels. Journal of Learning Disabilities, 47, 54-64.

Ravid, D. (1995). Language change in child and adult Hebrew: A psycholinguistic perspective. Oxford: Oxford University Press.

Ravid, D. (2001). Learning to spell in Hebrew: Phonological and morphological factors. Reading and Writing: An Interdisciplinary Journal, 14, 459-485.

Ravid, D. (2002). A developmental perspective on root perception in Hebrew and Palestinian Arabic. In J. Shimron (Ed.), Language processing and acquisition in languages of Semitic, root-based morphology (pp. 293-319). Amsterdam: Benjamins.

Ravid, D. (2006). Word-level morphology: A psycholinguistic perspective on linear formation in Hebrew nominals. Morphology, 16, 127-148.

Ravid, D., \& Bar-On, A. (2001). The Semitic root in language acquisition. GALA, 2001 Proceedings. University of Lisbon, Cidade universitaria-Faculdade de letras, Portugal.

Ravid, D., \& Epel-Mashraki, Y. (2007). Prosodic reading, reading comprehension and morphological skills in Hebrew-speaking fourth graders. Journal of Research in Reading, 30, 140-156. 
Vaknin-Nusbaum: Morphological awareness and reading abilities

Ravid, D., \& Malenky, A. (2001). Awareness of linear and nonlinear morphology in Hebrew: A development study. First Language, 21, 25-26.

Ravid, D., \& Schiff, R. (2006). Roots and patterns in Hebrew language development: Evidence from written morphology analogies. Reading and Writing: An Interdisciplinary Journal, 19, 789818.

Rispens, J. E., McBride-Chang, C., \& Reitsma, P. (2008). Morphological awareness and early and advanced word recognition and spelling in Dutch. Reading and Writing: An Interdisciplinary Journal, 21, 587-607.

Schiff, R., \& Lotem, E. (2011). Effects of phonological and morphological awareness on children's word reading development from two socioeconomic backgrounds. First Language, 31, 139163.

Schiff, R., \& Raveh, M. (2011). Maafianei haibud hamorfologi bmahalax zihui hamila bkerev korim im disleksia hitpatxutit [Characteristics of morphological processing during word recognition among readers with developmental dyslexia]. In D. Aram \& O. Korat (Eds.), Literacy and language: Relationship, bilingualism, and difficulties (pp. 399-413). Jerusalem: Magnes.

Schiff, R., \& Ravid, D. (2004). Vowel representation in written Hebrew: Phonological, orthographic and morphological contexts. Reading and Writing: An Interdisciplinary Journal, 17, 245265.

Schiff, R., \& Ravid, D. (2007). Morphological analogies in Hebrew-speaking university students with dyslexia compared with typically developing gradeschoolers. Journal of Psycholinguistic Research, 36, 237-253.

Schiff, R., Ravid, D., \& Levy-Shimon, S. (2011). Children's command of plural and possessive marking on Hebrew nouns: A comparison of obligatory versus optional inflections. Journal of Child Language, 38, 433-454.

Schwarzwald, O. (2001). Modern Hebrew (Vol. 127). Spotlight Poets. Retrieved from http:// poetryspotlight.com

Share, D. (2005). Disleksia b'ivrit: Hamorfologia v'haortografia haivriot [Dyslexia in Hebrew: Hebrew morphology and orthography]. Script-Orianut: Xeker, iyun, v'ma'as, 9, 9-39.

Share, D. L. (1995). Phonological recoding and self-teaching: Sine qua non of reading acquisition. Cognition, 55, 151-218.

Share, D. L. (2008). On the Anglocentricities of current reading research and practice: The perils of overreliance on an "outlier" orthography. Psychological Bulletin, 134, 584-615.

Shatil, E., Nevo, B., \& Breznitz, Z. (2007). Elul test. A standardized diagnostic test for learning disabilities. Haifa, Israel: Haifa University Publication.

Shimron, J. (2006). Reading Hebrew: The language and the psychology of reading it. Mahwah, NJ: Erlbaum.

Tong, X., Deacon, S. H., \& Cain, K. (2013). Morphological and syntactic awareness in poor comprehenders: Another piece of the puzzle. Journal of Learning Disabilities, 47, 22-33.

Tong, X., Deacon, S. H., Kirby, J. R., Cain, K., \& Parrila, R. (2011). Morphological awareness: A key to understanding poor reading comprehension in English. Journal of Educational Psychology, 103, 523-534.

Tyler, A., \& Nagy, W. (1989). The acquisition of English derivational morphology. Journal of Memory and Language, 28, 649-667.

Vaknin-Nusbaum, V., Sarid, M., Raveh, M., \& Nevo, E. (2016). The contribution of morphological awareness to reading comprehension in early stages of reading. Reading and Writing, 29, 19151934.

Vaknin-Nusbaum, V., Sarid, M., \& Shimron, J. (2016). Morphological awareness and reading in second and fifth grade: Evidence from Hebrew. Reading and Writing: An Interdisciplinary Journal, 29, 229-244.

Vaknin-Nussbaum, V., \& Shimon, J. (2011). Hebrew plural inflection: Linear processing in a Semitic language. Mental Lexicon, 6, 197-244. 
Vaknin-Nusbaum: Morphological awareness and reading abilities

Verhoeven, L., \& Carlisle, J. (2006). Morphology in word identification and word spelling. Reading and Writing: An Interdisciplinary Journal, 19, 643-650.

Verhoeven, L., \& Perfetti, C. A. (2003). The role of morphology in learning to read. Scientific Studies of Reading, 7, 209-217.

Verhoeven, L., \& Perfetti, C. A. (2011). Morphological processing in reading acquisition: A crosslinguistic perspective. Applied Psycholinguistics, 32, 457-466.

Wolter, J. A., \& Dilworth, V. (2014). The effects of a multilinguistic morphological awareness approach for improving language and literacy. Journal of Learning Disabilities, 47, 76-85.

Wolter, J. A., \& Gibson, F. E. (2015). Morphological awareness assessment and intervention to improve language and literacy. Seminars in Speech and Language, 36, 31-41.

Ziegler, J. C., \& Goswami, U. (2005). Reading acquisition, developmental dyslexia, and skilled reading across languages: A psycholinguistic grain size theory. Psychological Bulletin, 131, 3. 